\title{
Development of an inverse method for coastal risk management
}

\author{
D. Idier ${ }^{1}$, J. Rohmer ${ }^{1}$, T. Bulteau ${ }^{1}$, and E. Delvallée ${ }^{1, *}$ \\ ${ }^{1}$ BRGM, 3 av. C. Guillemin, 45060 Orléans Cedex 02, France \\ * now at: Océanide, Zone Portuaire de Brégaillon, 83502 La Seyne Sur Mer, France \\ Correspondence to: D. Idier (d.idier@brgm.fr) \\ Received: 6 March 2012 - Published in Nat. Hazards Earth Syst. Sci. Discuss.: - \\ Revised: 11 February 2013 - Accepted: 7 March 2013 - Published: 18 April 2013
}

\begin{abstract}
Recent flooding events, like Katrina (USA, 2005) or Xynthia (France, 2010), illustrate the complexity of coastal systems and the limits of traditional flood risk analysis. Among other questions, these events raised issues such as: "how to choose flooding scenarios for risk management purposes?", "how to make a society more aware and prepared for such events?" and "which level of risk is acceptable to a population?". The present paper aims at developing an inverse approach that could seek to address these three issues. The main idea of the proposed method is the inversion of the usual risk assessment steps: starting from the maximum acceptable hazard level (defined by stakeholders as the one leading to the maximum tolerable consequences) to finally obtain the return period of this threshold. Such an "inverse" approach would allow for the identification of all the offshore forcing conditions (and their occurrence probability) inducing a threat for critical assets of the territory, such information being of great importance for coastal risk management. This paper presents the first stage in developing such a procedure. It focuses on estimation (through inversion of the flooding model) of the offshore conditions leading to the acceptable hazard level, estimation of the return period of the associated combinations, and thus of the maximum acceptable hazard level. A first application for a simplified case study (based on real data), located on the French Mediterranean coast, is presented, assuming a maximum acceptable hazard level. Even if only one part of the full inverse method has been developed, we demonstrate how the inverse method can be useful in (1) estimating the probability of exceeding the maximum inundation height for identified critical assets, (2) providing critical offshore conditions for flooding in early warning systems, and (3) raising awareness of stakeholders and eventually enhance preparedness for future flooding events by allowing them to assess risk to their territory. The
\end{abstract}

next challenge is to develop a framework to properly identify the acceptable hazard level, as an input to the present inverse approach.

\section{Introduction}

\subsection{Context and current practices}

Coastal plain areas, with their increasing demographic and economic development over the last decades, are known as being a prime example of an "at-risk" territory. The concentrations of people and economic activities on the coastal fringe make these areas more vulnerable to shoreline retreat and coastal flooding. Vivid reminders of large coastal disasters are provided by the 1953 and 1962 North Sea storm surge events, which caused flooding of large areas in the south-western Netherlands and eastern England (Gerritsen, 2005) and in northern Germany (von Storch et al., 2008), respectively. Such flooding events illustrate the complexity of coastal systems and the limits of traditional flood risk analysis. Among other questions, these events raised issues such as: "how to choose flooding scenarios for risk management purposes?", "how to make society more aware and prepared for such events?" and "which level of risk is acceptable?". Though it remains still unclear to what extent the increased consequences of floods in the last decades are caused by the increase in magnitude or frequency of such events, rather than by the increased vulnerability of the coastal plain areas, it is generally acknowledged that flood risks are increasing worldwide and that the perspective of higher sea levels due to climate change might exacerbate these risks (Nicholls et al., 2006). 
Coastal risk management aims to avoid, reduce or eliminate intolerable risks (e.g. COMRISK, 2004). Management options can be designed to reduce the likelihood of the risks (e.g. strategic relocation to reduce the risk likelihood) or the consequences of the risk (e.g. early warning system and emergency management to reduce the consequence of flooding) or both. The concept of coastal flood risk management has been derived from safety science theory (Kirwan et al., 2002), with the risk being a combination of the probability of occurrence of a defined hazard and the magnitude of consequences. The following steps can be defined for coastal risk management (COMRISK, 2004): (1) identification of the nature and extent of flood risks, (2) understanding and addressing the relevant public perceptions, (3) establishing goals and standards with respect to flood risk, (4) establishing strategies and policies to achieve these goals, and (5) finally, minimizing the costs of achieving the goals, whilst ensuring the risk remains acceptable.

Practices for coastal risk management and governance have significantly evolved over the last decade due to progress in coastal engineering (and its capacity to assess risks), but also urged by increased vulnerability of coastal zones, linked with the increase in their urbanisation, industrialisation and tourism. For illustration, the reader can find a description of the French context in Deboudt (2010). During the last decade, extensive work towards an integrated flood risk analysis framework for coastal territories has been carried out within projects like FLOODSITE (Integrated Flood Risk Analysis and Management Methodologies, available at: http://www.floodsite.net). However, current practices in coastal risk management present several pitfalls and limits.

\subsection{Limitations of current practices}

\subsubsection{Social dimension}

The first limitation (L1) is that most risk assessment practices confine the risk concept to tangible physical impacts (e.g. structural damage). Yet, this vision may be too restrictive and may only constitute one part of the societal needs for natural risk management. Many other drivers (e.g. the society and the economy) are involved in decision making, territorial planning and societal relationships. What should be judged "at stake" cannot be defined by solely taking into account the physical dimension. In particular, Renn (2008a, b) clearly shows the need to combine natural science and social science approaches.

\subsubsection{Stakeholders participation}

A second limitation (L2) is that stakeholder (e.g.: national bodies, local authorities, emergency services and the public) participation is often weak. Results provided by risk assessments only constitute one part of the societal needs for natural risk management. In the present paper stakeholders are defined as any group or individual that "can affect or is affected by the achievement of an organisation's objectives" (Freeman, 2004). O'Sullivan et al. (2012) show that flood information in studied European countries is disseminated within a hierarchical framework from national bodies, through local authorities and emergency services to the public, such that this communication is typically one-way and top-down thus offering little chance for stakeholders engagement and feedback. This is also highlighted by the aim of the directive on the assessment and management of flood risks (2007/60/EC) to encourage an "active involvement of interested parties in the production, review and updating of the risk management plans" (Article 10 FD), and thus this favours the participation of citizens in the planning of their territory, such that stakeholders are really involved in the processes. As recommended by Meyer et al. (2012), stakeholders should be central to the process of flood hazard and risk mapping, and moreover, this process should be participatory. In particular, they emphasised that the needs of the different user groups can differ regarding flood hazard and risk information, whether their needs are focused on strategic planning, design of early warning systems or emergency management. Indeed, the main purpose of strategic planning is to avoid damage (e.g. physical, environmental and human). Therefore, it is at the prevention and adaptation level, such that information typically required include: flood extent and depth for events with different probabilities, damage maps (preferably aggregated over a full range of possible events), social, cultural and environmental risks and existing flood protection (Meyer et al., 2012). The main purpose of emergency planning is to avoid fatalities. It requires rapid access (maps) to assessments of the number of people who are at risk and who would need to be evacuated, as well as information on emergency management itself (e.g. assembly points, evacuation routes and hospitals) (Meyer et al., 2012). Early warning systems aim to estimate where flooding will likely occur during a storm event, and thus help emergency responses. In such systems, proper warning thresholds should be defined. Thus, the objectives and needs of these applications are quite different. Over the last decade, efforts have been made to involve stakeholders in the first steps of risk assessment processes (see Gamper and Turcanu, 2009 for a recent discussion on public participation), but their practical involvement in risk analysis still requires specific methodological developments (Renn, 2008a). Difficulties arise from the complex nature of the societal significance and acceptance of a risk, which not only depends on its physical dimension, but also on its societal perception, which is inherently a contextdependent question and is affected by social, political, cultural and economic factors. This was recently outlined by the FP7 CapHaz-Net project (Wachinger and Renn, 2010). The necessity to take into account risk perception in flood risk management is also underlined in DELTARES (2010). The joint issue of stakeholders' participation and risk perception raises the question of how to define risk acceptability, i.e. the 
"level of potential losses that a society or community considers acceptable given existing social, economic, political, cultural, technical and environmental conditions" (UNISDR, 2009). This is further discussed in Sect. 4.

\subsubsection{Risk scenarios}

A third major difficulty (L3) is how to choose the risk scenario. In theory, as reminded by Jonkman et al. (2008), the risk estimate should be based on a fully probabilistic analysis in which all possible scenarios and their consequences are included. Such an approach would require numerical elaboration as well as large computational resources. In practice, this is not achievable. This can explain why the European directive "on the assessment and management of flood risks (2007/60/EC)" (EU, 2007) recommends the use of at least three scenarios (one with a low probability of occurrence, or extreme event scenarios; one with a medium probability likely return period $\geq 100 \mathrm{yr}$; and one with a high probability, where appropriate) to cover a minimum of risk frequencies. To deal with the scenario issue, several options have been developed.

The first one is a deterministic method, named "Forcing event selection" (FEMA, 2005; Garrity et al., 2006): (1) it starts from offshore conditions scenarios (combination of wave, tide and surge conditions) characterised by a return period; (2) induced local hazards (flooding) on the territory are then estimated; (3) hazard mapping are overlaid on exposed vulnerable assets to assess the spatial distribution of damage; and (4) finally, the return period of the scenarios is commonly assigned to the damage mapping to end up with the risk mapping. This method is especially appropriate if a single parameter is believed to control the final water elevation (flood). In this case, selecting a $100 \mathrm{yr}$ return period parameter value corresponds to studying the $100 \mathrm{yr}$ final water elevation. A development of such an approach in the case of several parameters (for instance offshore water level $\xi_{e}$ and wave height $H_{S}$ ) controlling the final water elevation is to establish combinations having for instance a $100 \mathrm{yr}$ joint return period. Then these combinations are used as inputs to hydrodynamic models to estimate the water level at the coast $\left(\xi_{\mathrm{ec}}\right)$, and, among all the scenarios' results, the maximum final water elevation is retained. As outlined by FEMA (2011), the return period through this approach might be under-estimated compared to the true base flood probability. Such event scenario selection could be classified as a "direct" approach and thus is valid provided that the return period of hazard is equal to the return period of the offshore forcing conditions, which is not verified in all situations.

This limitation, highlighted by several authors (e.g. FEMA, 2005; Divoky and McDougal, 2006; Garrity et al., 2006), has given rise to alternative methods, such as the statistical "Response" methods, where the focus is on the return period of the hazard. One of those is the Monte-Carlo response method, such that input parameters are selected randomly from defined parameter distributions and are then used in a Monte-Carlo process to compute the distribution of flood extent and elevation (i.e. "Response", which is generally calculated with an empirical formula and more rarely by numerical models). Chini and Stansby (2012) developed a similar approach based on a statistical discretisation of the offshore conditions (wave height and water level), rather than on Monte-Carlo type computations. In the same spirit, reliability methods for coastal defence structures (e.g. Van der Most and Wehrung, 2005) have been developed based on the idea that various "failure mechanisms" can initiate a flood: not only extremely high water levels leading to overtopping, but also dike instability or failure, with the aim of identifying where the relatively weak locations in water defences lie. Using such "response" and "failure mechanisms" approaches should, in theory, avoid neglecting forcing conditions that are not individually significant, but whose combination can lead to dramatic consequences (as testified by the recent Xynthia event, 2010; Bertin et al., 2012), or to neglect coastal defence failures, as testified by the Katrina event (2005). Yet, the "Forcing event selection" or "direct" approaches remain widely used by risk practitioners (e.g. Garrity et al., 2006) for their relative easiness and efficiency, compared to the computational effort and length and quality of data records required for the second approach. This leads to uncertainties in the return period estimation and to process combinations being neglected.

\subsection{Toward the development of inverse methods for flooding risk management}

From the previous discussion, two main lines of improvement for the current risk assessment practices can be identified: how to better account within the risk assessment procedure what is considered at risk by the society (societal needs), and how to assess the likelihood of this tolerable risk. The objective of the present research, within an effort to overcome limitations L1, L2 and L3 is to (1) propose an inverse method for coastal flooding accounting for the complexity of the relationship between forcing conditions and water level at the coast, and (2) trigger participation, awareness and preparedness of stakeholders by placing the risk level as the starting point of the procedure. The essence of the proposed method is the inversion of the usual risk vision: the idea is to start from a threshold level (defined for instance by stakeholders) to finally obtain the return period of this threshold. Such an "inverse" approach would allow identification of all the offshore forcing conditions (and their occurrence probability) inducing a threat for critical assets of the territory. Whereas the traditional direct approach answers the question: what are the consequences if such scenario occurs? The proposed methodology aims at answering the question: what offshore conditions (and what are their likelihoods) can lead to the exceedance of a given threshold at the coast? The related 


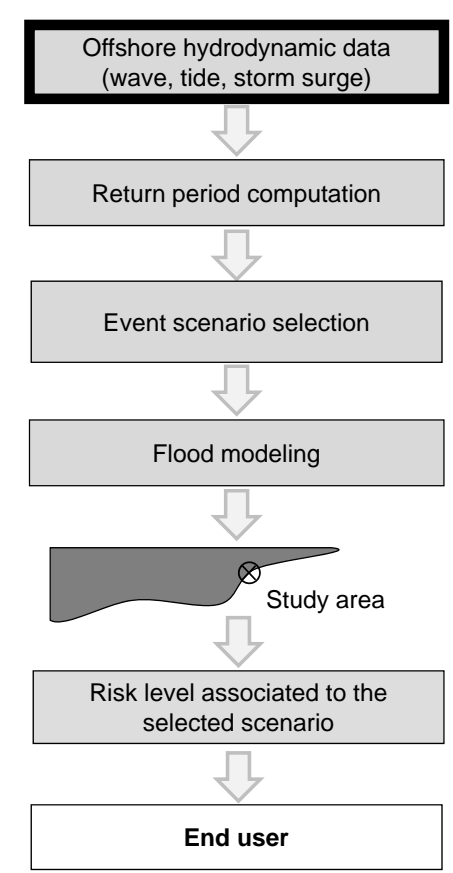

(a)

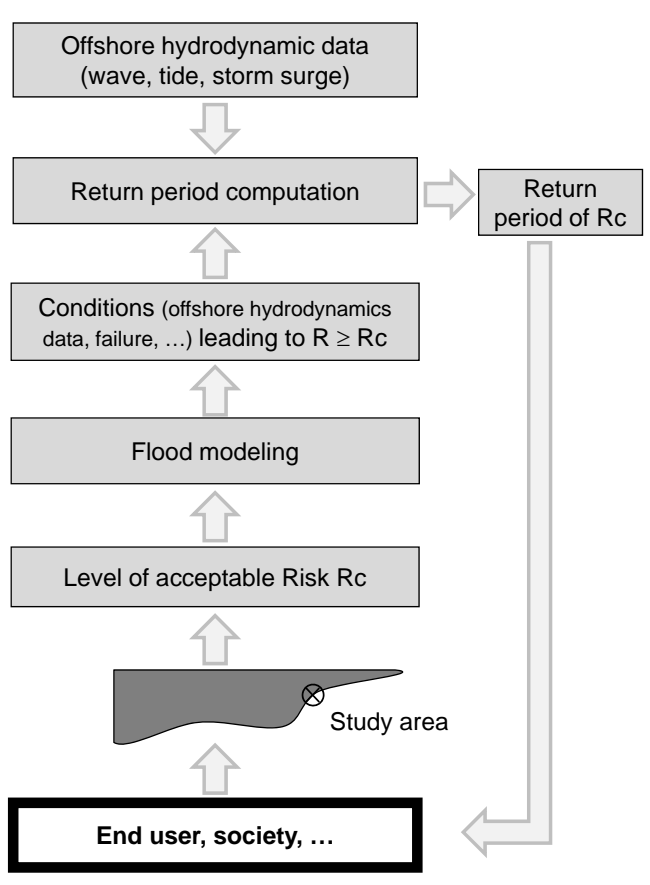

(b)

Fig. 1. Principle of direct (a) and inverse (b) approaches. The thick boxes indicate the main input of the approach.

question being: what should be the threshold at the coast and for which elements?

Such an approach has been, for instance, developed within the context of climate change, with the adaptation tipping points (ATP) method developed for flood risk. This method describes the extent to which the climate should change before current flood risk management is no longer efficient (Kwadijk et al., 2010). In such climate change contexts, whereas the traditional top-down approach answers the question: "what happens if such a climate change scenario occurs?", the ATP approach aims at answering "how much climate change and sea level rise can the current strategy cope with?". In hydrology, Cunderlik and Simonovic (2007) developed an inverse-type approach aiming at identifying the meteorological conditions leading to critical hydrological exposures. However, Cunderlik and Simonovic (2007) consider fewer physical dimensions in their model than in coastal systems because they only included meteorological precipitations as forcing conditions. For risk management for other perils inverse approaches are being developed. For example, Douglas et al. (2013) present a French national map for use within seismic building codes derived by targeting a certain level of acceptable risk of structural collapse, rather than a hazard level with a certain return period.

As a first step toward the development of a full inverse method starting from acceptability thresholds, the present paper focuses on the development of an inverse method accounting for the complexity of the relationship between forcing conditions and water level at the coast, and its application for an idealised, but one based on real data, test site. In the next section, we describe the principles for the inverse approach. Then, the application to a test site, located on the French Mediterranean coast, is presented. The potential applications, advantages and limitations of the inverse methodology are subsequently discussed, with a focus on how the present method could trigger participation of stakeholders (limitations L1 - societal needs and limitations L2 - stakeholders involvement). Then, conclusions outlying key issues for future research are drawn.

\section{Inverse method: principles, setup and development}

\subsection{Principles}

Figure 1 illustrates, by comparison with a more direct approach ("event-based"), what could be an inverse ("hazardbased") approach. This schematic representation shows that the input of the "direct" approach is the definition of the scenarios of offshore conditions (Fig. 1), whereas the input of the inverse approach is a hazard threshold. The proposed methodology is based on four main steps.

- Step 0: identify the hazard threshold. This step is accomplished in collaboration with different authorities depending on the needs (planning or early warning systems and emergency plans), regulations and safety standards, as well as the society in a broader sense 
(public). The determination of this input is discussed in Sect. 4.

- Step 1: identify all the offshore conditions leading to a hazard level larger than the threshold $R_{\mathrm{C}}$ (inversion step). This consists in estimating the boundary of the set of all scenarios of offshore conditions, which lead to $R_{\mathrm{C}}$ (named "critical" frontier). Note that in the present study, $R_{\mathrm{C}}$ is the threshold of water level at the coast, integrating storm surge, tide and wave set-up. This step already provides useful information for flood early warning systems.

- Step 2: estimate the return period of these offshore conditions (exceedance probability), i.e. the probability of exceeding the "critical" frontier.

- Step 3: feed-back with stakeholders and support decision making for coastal risk management using the information on the exceedance probability of the "critical" flooding. This is further discussed in Sect. 4.

The description here focuses on steps 1 and 2, considering step 0 as an input for the method. Issues related to steps 0 and 3 are discussed in Sect. 4.

\subsection{Inversion}

The objective of this step is to estimate the set of offshore conditions that can lead to the hazard threshold $R_{\mathrm{C}}$. This is achieved through inversion of the model used for hazard assessment. For clarity, let us formally define $F$ as the model used for hazard assessment so that $Y=F(X)=f\left(x_{1}, x_{2}, \ldots\right.$, $x_{N}$ ) where $Y$ represents the calculated hazard level and $X$ represents the vector of the forcing conditions $x_{i}$ ( $i=1$ to $N)$, which could be, like in the present study, the offshore water level $\left(\xi_{e}\right)$ and the wave height $\left(H_{S}\right)$. Given a hazard level $R_{\mathrm{C}}$, the first step of the "inverse method" consists in calculating the critical frontier of the set $S$ of offshore forcing conditions $X^{(j)}$ so that $F\left(X^{(j)}\right) \geq R_{\mathrm{C}}$. This formal problem does not have a unique solution and is referred to as the "inverse problem of the contour $R_{\mathrm{C}}$ ". This issue has an analogy with system reliability analysis, which implies estimating the failure probability of a system by integrating over the failure region defined by a contour (also named a "limit state"); see, for example, Haldar and Mahadevan (2000) for further details of reliability analysis. To solve this contour inversion problem, two strategies using directly $F$ can be proposed depending on their computation times.

When the model $F$ is not expensive to evaluate, the "inverse problem" can merely be solved in a forward manner consisting in the systematic direct evaluation of the model $F$ using a regular grid in the forcing conditions space. To illustrate, let us consider a regular grid designed for 30 configurations of $\xi_{e}$ varying by a constant increment step between 0.25 and $1.50 \mathrm{~m}$ and 30 configurations of $H_{S}$ by a constant increment step varying between 0.5 and $7 \mathrm{~m}$. In two dimensions, the desired contour can then be extracted using, for instance, Matlab's ${ }^{\Theta}$ function contourc, the accuracy of the solution being dependent on the grid increment, hence on the grid size.

Such an approach may, however, become rapidly prohibitive when using computational, time-consuming models (with run times varying from hours to days). This issue has given rise to numerous studies either relying on appropriate grid computing architecture (e.g. Boulahya et al., 2007) or on the use of meta-models (also named response surfaces or surrogate models). The latter technique consists in replacing the true model $F$ by a mathematical approximation that predicts the model responses with a negligible computation time cost. In the coastal domain, the application of the meta-modelling approach to the specific case of contour estimation of computationally intensive numerical codes is illustrated by Rohmer and Idier (2012), but it still remains a matter of continuing research.

\subsection{Estimation of the return period}

The inverse modelling discussed above provides the set $S$ of combinations $\left(\xi_{e} ; H_{S}\right)$ leading to a water level at the coast higher than the maximum acceptable level, i.e. a water level at the coast $\xi_{\text {ec }}$ such that $\xi_{\text {ec }} \geq R_{\mathrm{C}}$. The next step is to compute the return period $T_{\mathrm{R}}$ of this set $S$, also called the annual exceedance probability $\left(1 / T_{\mathrm{R}}\right)$. To compute that return period, there is a need for a long enough time series of $\xi_{e}$ and $H_{S}$. This time series can either come from in-situ measurements or from model outputs.

The offshore wave height and water level are generally not completely independent since a storm will both generate both a storm surge (increase in the water level) and higher waves (Hawkes et al., 2002; HR Wallingford, 2000a). Thus, a relevant approach is to take into account the dependency between these two hydrodynamic components. For that, the method of joint probability analysis can be used. By definition, this method computes the probability of occurrence of events in which two or more partially dependent variables simultaneously exceed given values. A joint probability analysis software package for coastal applications named JOIN-SEA was developed during a Defra-funded research programme (Hawkes et al., 2002). Details of the theory, development, testing and validation of JOIN-SEA are given in (HR Wallingford, 2000a, b). There are five main stages in the analysis:

i. preparation of input data consisting of independent combinations $\left(\xi_{e} ; H_{S}\right)$. These combinations are simultaneous observations of the two variables at the offshore analysis point (before the breaking of waves);

ii. fitting of marginal distributions for $\xi_{e}$ and $H_{S}$ (Generalized Pareto Distribution or GPD); 


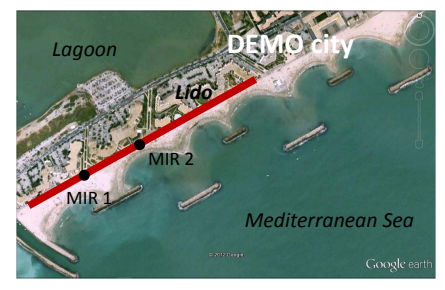

(a)

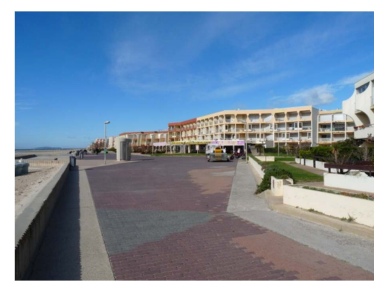

(b)

Fig. 2. Site (DEMO City) location with the sea wall position (red line) and observation points (MIR1 and 2) where the inversion calculation is performed (a) and photo of the sea wall from point MIR 2 (b).

iii. fitting of a statistical model of dependence between $\xi_{e}$ and $H_{S}$;

iv. long-term simulation using a Monte-Carlo process generating millions of combinations $\left(\xi_{e} ; H_{S}\right)$ that have the same statistical characteristics as the original data;

v. analysis of joint exceedance extremes. It provides isojoint exceedance return period points in the variable space $\left(\xi_{e} ; H_{S}\right)$ : for each point $(x, y)$ on one of these iso-return period contours, the probability of the event $\left\{\xi_{e}>x, H_{S}>y\right\}$ is such that this event occurs on average once during the return period.

In our specific study, we are interested in the return period of $S$ (see Fig. 8, red area), not on any joint exceedance return period of both $\xi_{e}$ and $H_{S}$ (see Fig. 8, green area). Therefore, once stage (iv) has been performed, the return period of $S$ is calculated using the following formula:

$R P(S)=\frac{1}{E \times \operatorname{Pr}(S)}$

with $\operatorname{Pr}$ the probability of exceedance of $S$ such that $\operatorname{Pr}(S)=$ $\frac{1}{N} \sum_{i=1}^{N} \mathbf{1}_{X \in S}\left(X_{i}\right) . E$ is the number of observations per year, $N$ is the number of simulated combinations, $X$ represents a couple $\left(\xi_{e} ; H_{S}\right)$, and $\mathbf{1}_{X \in S}$ is the indicator function of $S$, such that if $X_{i} \in S, \mathbf{1}_{X \in S}\left(X_{i}\right)=1$, otherwise $=0$.

\section{Application}

\subsection{Study site and hazard threshold}

In this study the site application is based on a real case, but the results are mainly for demonstration purposes. Furthermore, the method is applied for strategic planning, such that it accounts for small impact-high frequency events, and such that the hazard threshold is defined as the maximum acceptable hazard level. The presented results are not to be interpreted as a definitive risk assessment. That is why we choose to use a fictive city name. In the present case, the study site

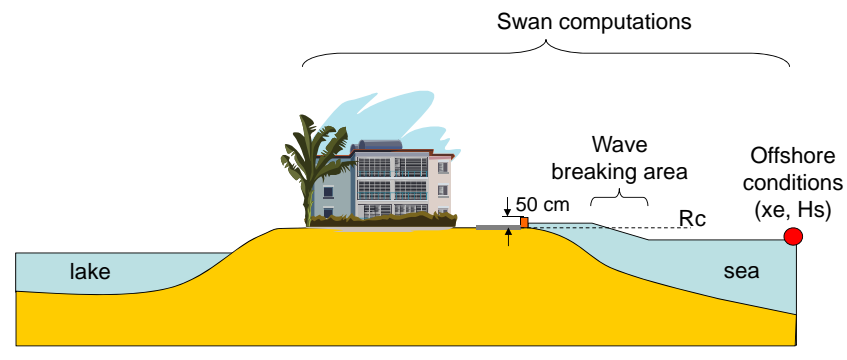

Fig. 3. Cross-shore scheme of the study case.

is a city, which we called DEMO in this demonstration exercise, lying on a lido protecting the lagoon.

This site is located on the Mediterranean coast (Fig. 2). A regional study (Vinchon et al., 2008) identified that the lido is a regional "hot-spot". DEMO is characterised by significant touristic activities. At the sea-front, there are pedestrian areas, which have already been flooded in, at least, two storms: 6-8 November 1982 and 4 December 2003. This pedestrian area is limited by a sea wall having a height of about $50 \mathrm{~cm}$ above the pavement (Fig. 3) but with some openings.

The determination of the maximum acceptable hazard level and the associated tolerable return period is relatively rough in the present paper, for demonstration purposes. First, we assume that it is intolerable that the narrowest part of the town starts to be flooded. Here, we are typically referring to the case of small impact (flooding of ground floor of coastal buildings). Knowing that the foot of the open sea wall is located $2.15 \mathrm{~m}$ above the vertical reference (IGN), it implies that the total water level, including storm surges, tide, wave set-up and run-up should not be higher than this value. It should be noted that for demonstration purposes, the hazard threshold is not related to characteristics of the flood itself (water depth and velocity) but to the water level at the coast. Secondly, to identify the minimum acceptable return period $\left(T_{\mathrm{RC}}\right)$ of such a flood, we focus on individual acceptability. For this purpose, some results on individual perception from the national research project MISEEVA (Vinchon et al., 2010) are used. Within surveys, the following question has been asked to inhabitants and merchants of DEMO city: "Above which frequency of sea flooding inundation of your house, would you leave your home?". Figure 4 illustrates the survey results based on the $94.5 \%$ of interviewees who answered. Return periods of 1 and $10 \mathrm{yr}$ are the most common answers with a proportion of 22 and $17 \%$, respectively. Thus, we are in the case of a maximum acceptable hazard characterised by a small impact and high frequency flooding. This means that most of the permanent residents experiencing minor floods in their homes, on average every year or every ten years, consider that it is above what they can afford and hence they would move. Here risk acceptability is focused on the inhabitants of the lido. Averaging all the answers gives a minimum acceptable return period $T_{R C}$ 


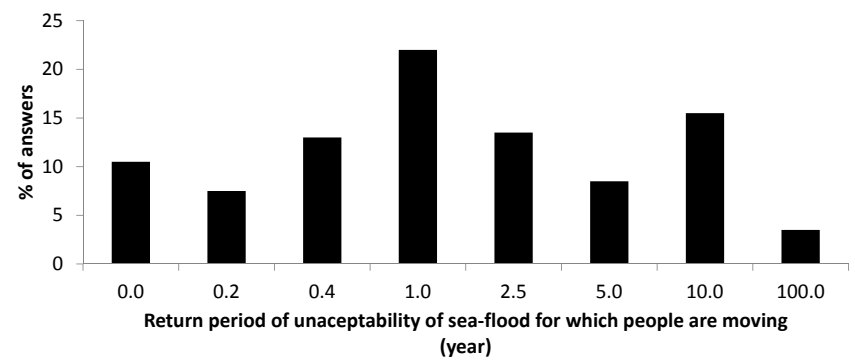

Fig. 4. Threshold of acceptability to sea flooding, based on the answers of residents and shopkeepers of DEMO city to the question: Above which frequency of sea-flooding inundation of your house, would you leave your home? The results exclude the $5.5 \%$ who did not answer. Data provided by the MISEEVA project (Vinchon et al., 2010).

of $6.5 \mathrm{yr}$. This value is used henceforth. This value implies that DEMO city should not be flooded more than once every $6.5 \mathrm{yr}$ on average and means that $70 \%$ of the interviewees would move in case it is flooded more than once every $6.5 \mathrm{yr}$ (Fig. 4). Such proportion would have significant consequences on the local activities. We make the assumption that this critical flooding return period means it is intolerable that water enters the area through the sea wall openings more than once every $6.5 \mathrm{yr}$, and specifically at points MIR1 and MIR2 (Fig. 2) which are just in front of connection roads with the lagoon.

It is worth noting that the level of what is tolerable or not depends also on the risk culture and the perception of danger. In the present demonstration, we assume that the main concerns of the society are to preserve economical activities and tourism of the DEMO city, which contributes to a large extent to the image and the attractiveness of the region. Obviously, for another site or for another type of application (e.g. early warning or emergency management), the level might be different. For example, it might correspond to a critical impact such that fatalities are intolerable. Then, the hazard level $\left(R_{\mathrm{C}}\right)$ might be such that the water level does not reach the first storey of buildings.

\subsection{Inversion}

\subsubsection{Model to inverse}

For sake of clarity, we assume that the flooding of the lido is not influenced by the lagoon, and we also neglect the influence of the lido on the submersion phenomenon. First, we remind the reader that the water level at the coast $\xi_{\text {ec }}$ results from the offshore water level $\xi_{e}$ (tide and meteorological storm surge) and the run-up resulting from two dynamical processes, which are the wave set-up $\eta$ and the swash $S$. Here, we set a modelling strategy to account for these three contributions $\left(\xi_{e} ; \eta ; S\right)$. For the offshore water level contribution, we assume that $\xi_{e}$ induced by storm surges

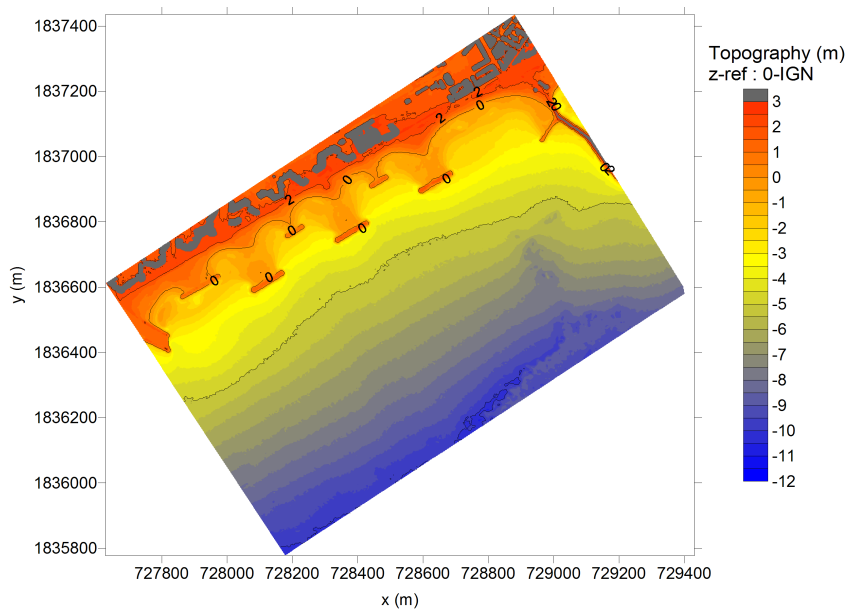

Fig. 5. 2-D domain of the SWAN implantation used for the inversion.

and tide is uniform in the local area. For the set-up and run-up induced by waves, we need a more sophisticated approach. First, the wave set-up $\eta$ is computed using the code SWAN (Booij et al., 1999). It solves the wave action equation and provides wave spectra and wave set-up. At the offshore boundary, uniform sea level and wave height are imposed. The bathymetric and topographic data used here have been obtained through lidar measurements (data provided by DREAL LR), as well as bathymetric surveys (data provided by SHOM). The grid size is $2 \mathrm{~m}$ (Fig. 5). Second, to compute the swash-induced elevation $S$, we use the formulation of Stockdon et al. (2006). Based on the assumption of reflective beach, the analysis of the equations proposed in Stockdon et al. (2006) shows that we can, as a first approximation, assume that $S$ is equal to the set-up. Thus the total maximum water level $\xi_{\mathrm{ec}}$ at the beach is calculated as follows:

$\xi_{\mathrm{ec}}=\xi_{e}+2 \eta$

The inversion is based on this model (SWAN and the swash formula of Stockdon et al., 2006).

\subsubsection{Inversion results}

We inverse the system to provide offshore conditions in the variable space $\left(\xi_{e} ; H_{S}\right)$. The wave period and the wave direction are fixed at their most frequently observed values. For the present case, the analysis of a few years' worth of wave data from a buoy located in the south-east of the area indicates that the dominant wave incidence angle is $105^{\circ}$ (corresponding to a nautical wave direction of $135^{\circ} \mathrm{N}$ ), for a wave period of $7 \mathrm{~s}$. Thus, the return period of the combination $\left(\xi_{e}\right.$; $H_{S}$ ) is computed for a wave dataset restricted to this fixed wave period and direction.

Given the relatively moderate computational time cost of the considered numerical model (on average one simulation requires $15 \mathrm{~min}$ to run), we focus on a "grid-based" approach 

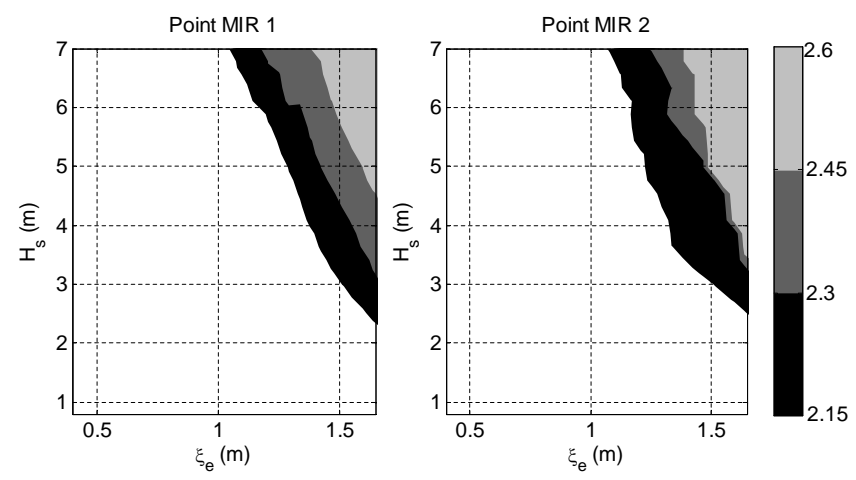

Fig. 6. Total water level $\xi_{\mathrm{ec}}(\mathrm{m})$ at the beach versus offshore water level $\xi_{e}$ and offshore significant wave height $H_{S}$.

and simulated $30 \times 30$ different configurations of the offshore forcing conditions $\left(\xi_{e} ; H_{S}\right)$ using a cluster of ten computer units, which enables the overall computation to take less than one day. The results at the MIR1 and MIR2 locations (Fig. 6) indicate there is a range of couples $\left(\xi_{e} ; H_{S}\right)$ such that the threshold value of the total water level at the beach is exceeded. For instance, at point MIR1, for an offshore water level of $1.5 \mathrm{~m}$ (compared to the vertical IGN reference), an offshore significant wave height of $6 \mathrm{~m}$ would induce a total local water level exceeding the critical value and thus leading to water entering through the wall openings.

\subsection{Return period of the hazard threshold}

\subsubsection{Offshore time series generation}

Ideally, the inversion step would provide water levels and wave heights at a location where continuous measurements are made (permanent buoys or sensors). In some places, this is indeed the case. In the present study, there are no observations of water levels or wave conditions at the selected site. Thus, there is a need to find a time series dataset, corresponding to the conditions at the offshore boundaries of the SWAN implementation (Fig. 5). For this purpose, we use numerical model outputs. Concerning the waves, outputs of the WW3 model, implemented in this area by Ardhuin et al. (2010), are used. The closest node of the WW3-grid having the same water depth as the offshore boundary of the SWAN model is used. This point is located $1 \mathrm{~km}$ south-west of the DEMO site. The quality of the WW3 implementation in Mediterranean Sea has been investigated by Ardhuin et al. (2007) who show that the best fit slope between the modelled and observed wave heights is about $0.84-0.87$ for the WW3 model forced by ALADIN wind data (Météo-France). Thus, for the demonstration, we corrected the WW3 outputs to compensate for this error, by multiplying the significant wave height by a factor of 1.18 (i.e. $1 / 0.85$ ).

Furthermore, for the water level, numerical computations are performed using the MARS2DH model (Lazure and

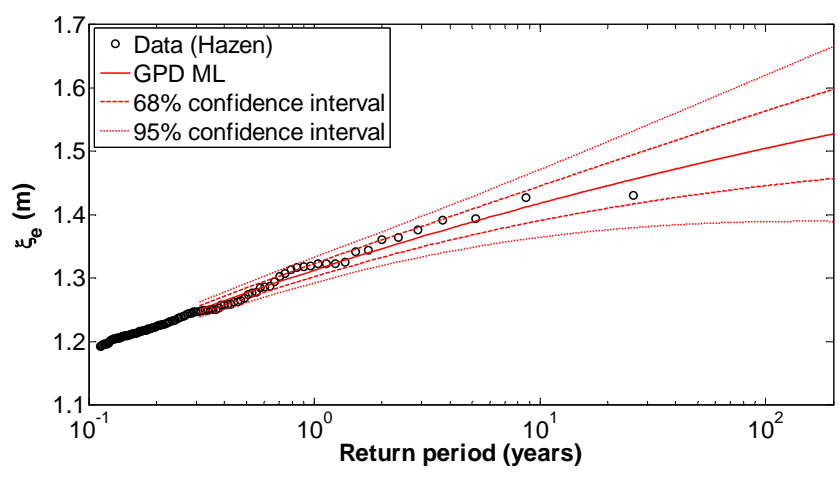

Fig. 7. Best fit of the GPD model and confidence intervals for the marginal distribution of $\xi_{e}$. Parameters of the GPD calculated with the method of maximum likelihood. Threshold: $1.19 \mathrm{~m}$.

Dumas, 2008). The background of the implementation of the MARS2DH model for the study area as well as its validation is presented in Pedreros et al. (2011). Here, the simulations are based on FES2004 (Lyard et al., 2006) for the tidal boundary conditions and on the Climate Forecast System Reanalysis (CFSR, Saha et al., 2010) for wind and pressure.

Finally, a sea level dataset of $13 \mathrm{yr}$ and a wave dataset of $5 \mathrm{yr}$ are provided.

\subsubsection{Return period of $R \geq R_{\mathrm{C}}$}

The preparation of input data (selection of independent events) for the joint probability analysis was performed in two stages. First, one event per day was selected taking the daily maximum of $H_{S}$ with a minimum $12 \mathrm{~h}$ duration between two successive events. Then, to each of these $H_{S}$ peaks, the maximum of $\xi_{e}$ in a temporal window of $12 \mathrm{~h}$ centred on the peak of $H_{S}$ were associated. This is a conservative approach that allows capturing the highest values of the water level signal. In all, 231 events per year were selected in this way.

For the calculation of marginal distribution of $\xi_{e}$, instead of using the default JOIN-SEA distribution that is based on waves and water levels data covering the same temporal period (i.e. $5 \mathrm{yr}$ ), we fitted a new GPD for $\xi_{e}$ using all available data (13 yr). The parameters were calculated using the method of maximum likelihood. The threshold choice was selected using several techniques (based on visual appreciation of quantile-quantile plots, residual life plot, and statistical tests $\mathrm{Chi}^{2}$, Kolmogorov-Smirnov and so forth; see, e.g. Coles, 2001). A threshold of $1.19 \mathrm{~m}$ was considered as producing the best fit (Fig. 7).

The statistical model for dependence between $\xi_{e}$ and $H_{S}$ is a mixture of two bivariate normal distributions (HR Wallingford, 2000a). This model is fitted to the data after conversion of the variables to normal scales.

We simulated $10000 \mathrm{yr}$ in the long-term simulation stage of the JOIN-SEA analysis which represents 
Table 1. Return period of $S$ (combinations that lead to exceedance of $R_{\mathrm{C}}$ ) and $95 \%$ confidence interval for both study points.

\begin{tabular}{ccc}
\hline Point & $\begin{array}{c}\text { Return period } T_{\mathrm{R}} \\
\text { of } S \text { (years) }\end{array}$ & $\begin{array}{c}95 \% \text { confidence } \\
\text { interval (years) }\end{array}$ \\
\hline MIR1 & 4.4 & {$[4.2 ; 4.6]$} \\
MIR2 & 2.3 & {$[2.2 ; 2.4]$} \\
\hline
\end{tabular}

2310000 combinations $\left(\xi_{e} ; H_{S}\right)$. The last stage of the analysis leads to estimation of the curves of iso-joint exceedance return period (black curves on Fig. 8). Using the limit provided in the inversion step (red line on Fig. 8) and Eq. (1), allows estimation of the return period of set $S$ or, in other words, the probability of exceedance of the critical water level at the coast $R_{\mathrm{C}}$, for points MIR1 and 2. Figure 8 illustrates the result for point MIR1. This exercise leads to a return period of $R\left(=\xi_{\mathrm{ec}}\right) \geq R_{\mathrm{C}}$ comprised between 2.3 (point MIR2) and $4.4 \mathrm{yr}$ (point MIR1) (Table 1).

Table 1 and Fig. 6 show the spatial heterogeneity of the return period of $R \geq R_{\mathrm{C}}$ along the coast, with point MIR2 having, for instance, almost twice the chance to encounter a sea level exceeding the critical value than point MIR1.

\subsection{Use for coastal risk management}

The return periods at points MIR1 (4.4 yr) and MIR2 (2.3 yr) are smaller than the acceptable one $\left(T_{\mathrm{RC}}=6.5 \mathrm{yr}\right)$. In the light of this result, the acceptability threshold of $6.5 \mathrm{yr}$ should be re-discussed (with decision-makers, stakeholders and populations). This iteration has three main purposes. First, one aim is to increase the stakeholder's awareness of risks. Indeed, as illustrated by Kievik and Guttelling (2011), a certain level of risk awareness is required to encourage the public to adopt self-protective behaviour. A second purpose is to help and encourage them to hierarchize their priorities in terms of coastal planning and management. This prioritisation can be done based, for instance, on multi-criteria decision making (Karlsson, 1996) or group consensus methods (Gervais and Pepin, 2002). Lastly, one is to help the decision makers weigh up the different risk management actions, for instance strengthen the coastal defences (but at what cost?), invest in flood-proofing of buildings, or improve warning systems (DELTARES, 2010).

More particularly, two possible outcomes of this feedback can be envisaged. The first one is if it is decided that the acceptable return period of the hazard threshold remains at the original value of $6.5 \mathrm{yr}$, coastal risk management should then focus on preventive actions at the level of the city defences (e.g. increase in control of dikes: maintenance; reinforcement when required; "build with nature", like flood protection by beach nourishment; Delta Committee, 2008) or at the planning level (e.g. urban development). A second possible outcome of the feedback process is to accept a shorter return period than $6.5 \mathrm{yr}$ (e.g. $2 \mathrm{yr}$ ), but under the condition that an

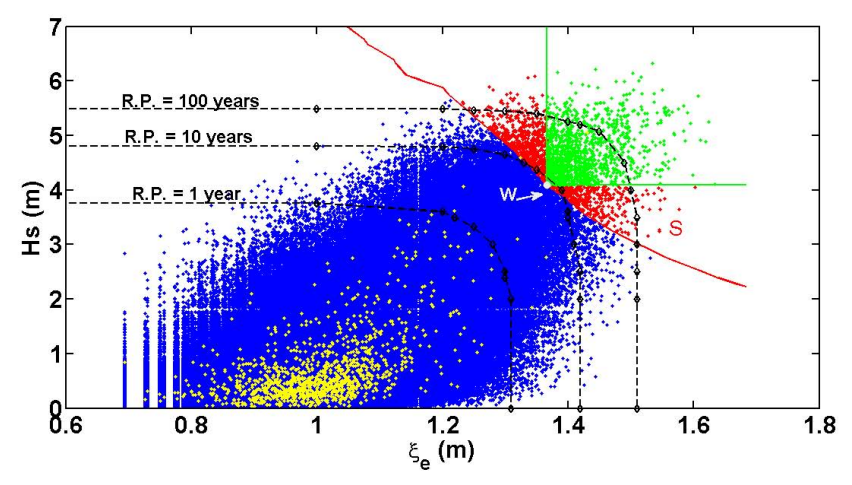

Fig. 8. Illustration of the results for point MIR1. The original data points (independent events) are represented by yellow dots while simulated combinations are represented by blue dots. The black curves represent the contours of iso-joint exceedance return period. The red curve is the limit of $S$ (combinations that lead to exceedance of $R_{\mathrm{C}}$ ) which is represented by red dots. The joint exceedance domain for the combination $W$ which represents the worst case of $S$ is pictured in green (i.e. the combination whose joint exceedance return period is the lowest).

early warning system is set up allowing for minimisation of the economic, environmental and human cost of flooding.

\section{Discussion}

The initial development of the inverse approach had two main objectives: improve hazard assessment; and improve awareness and preparedness, preparedness being defined as the "knowledge and capacities developed by governments, professional response and recovery organisations, communities and individuals to effectively anticipate, respond to, and recover from the impacts of likely, imminent or current hazard events or conditions" (UNISDR, 2009). How the method contributes to these two objectives is discussed here.

\subsection{Hazard assessment}

\subsubsection{A “decoupled-strategy"}

From a physical point of view, as stated before, traditional (direct) approaches used to build coastal flooding maps are based on offshore scenarios propagated to the coast (eventbased approach), which can present strong limitations (denoted L3, as described in the introduction).

In the present study, we estimated the return period of a total water level exceeding $R_{\mathrm{C}}$ at point MIR1 as $4.4 \mathrm{yr}$. A scenario-based approach on point MIR1 would have probably induced the selection of the combination represented by point W on Fig. 8, which corresponds to the worst case of $S$ (i.e. the combination whose joint exceedance return period is the lowest), leading to a return period about two times larger $(8.3 \mathrm{yr})$ than the real return period $(4.4 \mathrm{yr})$ of the hazard 
characterised by $R \geq R_{\mathrm{C}}$. This factor of two has already been identified in the literature (Hawkes et al., 2002; Garrity et al., 2006). This illustrates that selecting a scenario, based on the choice of an offshore couple having a joint exceedance return period of $T$ years, will likely lead to a hazard map of a return period possibly closer to $T / 2$ years than to $T$ years. Furthermore, as mentioned by Jonkman et al. (2008) in a study of flood risk in South Holland, in future analyses special attention should be given to more extreme flood scenario than the ones they studied, because unlikely extreme scenarios already happened in the past (e.g. Katrina induced flooding in 2005). In principle, the proposed inverse method could be a way to better identify the likelihood of some unlikely extreme hazard level at the coast. Thus, the inverse method we propose limits the bias induced by the a priori selection of a specific event scenario and accurately computes the return period of hazard being larger or equal to the critical one (exceedance), as the "Response" methods (see Garrity et al., 2006). This allows overcoming limitation L3.

Moreover, the present method further improves the "Response" methods thanks to its decoupling of the different phases: (1) a first step consists in estimating all the forcing offshore conditions so that the water level at the coast exceeds the maximum acceptable level $R_{\mathrm{C}}$ (step 1); (2) a second step uses the set of offshore conditions (i.e. a critical frontier defined in the domain of offshore conditions) to compute the return period associated with the event "exceeding $R_{\mathrm{C}}$ " by means of a statistical analysis of extremes and of a Monte-Carlo-based approach (step 2). Such an approach allows computation of the critical frontier in a deterministic fashion, i.e. independently from any notion of probability. This presents several advantages. First, this allows an in-depth exploration of the domain of offshore conditions to identify the critical frontier, either using a grid-based approach as used here for the test case or a more advanced method using a metamodelling technique (Rohmer and Idier, 2012). Such contour information can be useful, for instance, in forecasting systems (e.g. PREVIMER - http://www.previmer.org, NIVMAR - http://www.puertos.es/oceanografia_y_meteorologia/ redes_de_medida/index.html), early warning systems (Harley et al., 2012; Ciavola et al., 2011; Norbiato et al., 2008; Safecoast, 2008), or coastal observatories (such as the Channel Coastal Observatory, http://www.channelcoast.org). Secondly, this makes the step involving statistical analysis of extremes independent, which can be of great interest when the return-period calculation has to be updated by integrating, for instance, scenarios of climate change. The advantage of this "de-coupled strategy" is illustrated in the inverse approach developed by Cunderlik and Simonovic (2007), which aims at better integrating changing climatic conditions in flood-risk modelling. Thus, even if climate and offshore conditions are changing, the method does not require the whole procedure to be repeated (contrary to the "response" method), but only to repeat step 2 .

\subsubsection{Uncertainties in inversion and exceedance return period}

Within the inversion step, several uncertainties can be identified. First, the model by itself contains uncertainties. To reduce it, the first step is to choose the model in accordance to the flooding regime (direct inundation, overtopping, breaching) associated with the selected threshold: a very high threshold of water level at the coast for instance implies a direct inundation, whereas a threshold just above coastal defense height implies mainly overtopping processes. For a direct inundation regime, several approaches could be used, neglecting overtopping, like for instance the "bathtub" method (e.g. based on hydrodynamic model providing water level at the coast, the water level being projected inland using GIS) or full 2-DH modelling (Hervouet and van Haren, 1993). For the overtopping regime, other approaches are required, either integrating overtopping calculation formulae, or describing the full dynamics using Boussinesq-type models (Cheung et al., 2003; Wadey et al., 2012; Chini et al., 2013). In this paper, the model we used was simple, designed for demonstration purposes. The use of the most sophisticated models (fully nonlinear weakly dispersive models, like the one developed by Bonneton et al., 2011) would allow for a reduction in the model uncertainties used for the inversion, but may require more sophisticated approaches for the inversion, as discussed in Sect. 2.2. For instance, Rohmer and Idier (2012) developed a strategy based on the kriging meta-modelling technique combined with an adaptive sampling procedure aimed at improving local accuracy in the regions of the offshore conditions that contribute most to the estimate of the targeted contour (threshold). They show that the critical offshore conditions can be accurately estimated using a limited number (a few tens) of computationally intensive hydrodynamic simulations.

In addition to the choice of the most relevant model, there are uncertainties to which we should pay attention, as for direct approaches. Part of these uncertainties can be taken into account within the meta-model technique. First, most of the hydrodynamic models are validated using observations on a site for a range of hydro-meteorological regimes. This validation procedure allows estimating part of the model uncertainty corresponding to the discrepancies between the observations and the model predictions. Accounting for this uncertainty in the inversion procedure implies integrating it in the construction phase of the meta-model (see Rohmer and Idier, 2012) following for instance the approach proposed by Kennedy and O'Hagan (2001). However, as for direct approaches, we should be careful when using models outside the regimes for which they have been validated on site. Second, attention should be paid to input parameters, which can be associated to uncertainty (e.g. bathymetry varying in time, friction coefficient varying in space and time), such that for a given configuration of offshore conditions, the model gives different results. Integrating such parameter uncertainty in 
the inversion procedure remains a matter of ongoing research. The recent advances in optimisation of stochastic functions (Picheny et al., 2013) could be a starting point for such investigations.

Finally, the offshore dataset quality can influence the results on exceedance return period. In the present study, it has been constructed using a modelling approach. Thus, there are some uncertainties in the values that have been used. This source of uncertainty would vanish for locations where wave data buoys and tide gauges are available. This illustrates that the present approach would be especially useful where hydrodynamic data exist offshore the site of interest. Hence, there is a need for hydrodynamic data monitoring in the vicinity of the identified vulnerable sites, in addition to operational models.

\subsection{Coastal risk management, awareness and preparedness}

The second objective of the inverse approach is to improve the authorities and society "awareness and preparedness", by raising the question of risk acceptability and by triggering stakeholders' participation.

One of the potential advantages of the proposed inverse approach is that the final result is a return period of a hazard level identified as the threshold above which such a hazard is intolerable. A comparison of that return period with the one considered previously as acceptable should raise awareness of the actual risk. Thus, in the inverse approach, the input determination (hazard threshold) should be associated with a "realistic" point of view of the acceptable likelihood of the threshold being exceeded.

As an indirect advantage, the proposed method would allow reliance on a strong implication of the stakeholders (e.g. society and decision-makers). This transfer of knowledge should be useful not only for territorial planning, but also for preparedness and emergency purposes. This seeks to overcome limitation L1 (as described in the introduction).

The present inverse method requires the identification of a hazard threshold $\left(R_{\mathrm{C}}\right)$ for the input. The way this threshold is defined and the nature of this threshold depend on the needs of the stakeholders. Furthermore, this threshold has to be identified in collaboration with stakeholders to ensure both substantive (integration of stakeholders' knowledge) and instrumental (trust of stakeholders) rationale (Meyer et al., 2012). As highlighted in the introduction, the determination of hazard threshold raises the question of risk acceptability. A detailed discussion of risk acceptability is beyond the scope of this article. Nevertheless, we discuss what would be the benefit of the inverse method within risk evaluations based on acceptability. A widely used tool for displaying risk is the frequency/impact (also named frequency/consequence) graph (e.g. Ballard, 1993), as schematically depicted in Fig. 9. On this basis, the critical limit between what is acceptable or not can be defined. This limit can either be small

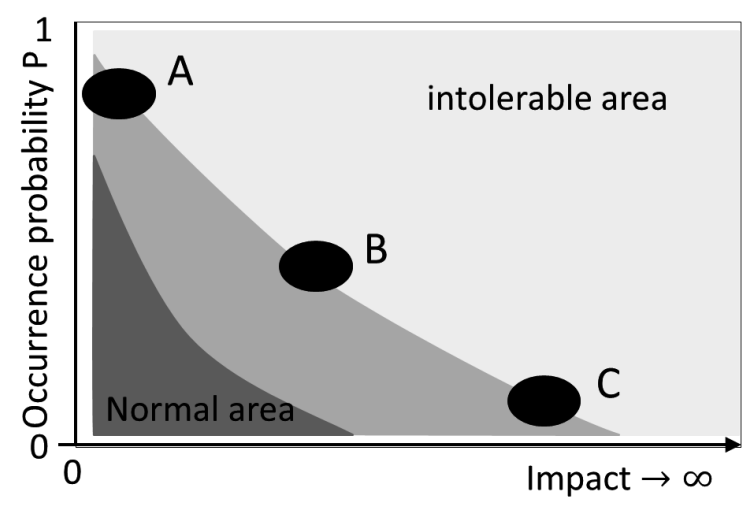

Fig. 9. Risks areas: normal, intermediate and intolerable. Adapted from Farmer (1967). Three cases are depicted. Risk event A: low impact/high probability of occurrence; Risk event B: intermediate case; Risk event C: high impact/low probability of occurrence corresponding to a catastrophic event.

impact/high probability (point A), or high impact/low probability (C), and both could be "intolerable" for the society. In the case of flooding, Haimes (2004) found that people are "often more concerned with low probability catastrophic events than with more frequently occurring but less severe accidents". As stated by Renn (2008a), investigation of the perception of rare but possible catastrophic events shows that probability hardly plays any role. In other cases, for smaller impact events, society accepts that they happen up to a critical occurrence probability (or return period), above which they cannot be tolerated or afforded anymore (Renn, 2008a). Even if there are some differences, one of the most consistent findings within and across cultures is that usually the same concepts (e.g. dread and unknown risks) emerge, but receiving different priorities (Kasperson, 1986), leading to different levels of risk acceptance. In principle, the inverse approach would allow these to be taken into account in various contexts, with difficulty remaining in reaching a consensus in the definition of the acceptability thresholds.

To account for the complex question of risk acceptability, some frameworks have been proposed. Within Europe some countries like the Netherlands defined flood risk safety standards, for instance, in terms of fatalities (i.e. probability to avoid a given number of fatalities). Similar safety standards being defined for other risk (e.g. liquefied petroleum gas stations and airports), these standards allow comparison and prioritisation between risk reduction actions (Bottelberghs, 2000; Vrijling et al., 1995). In particular, the one adopted in the Netherlands (Vrijling et al., 1995), based on the acceptable level of risks to persons, at local and national levels. The two discussed point of view (individual and societal) resulted in the definition of three risk criteria: a personally acceptable level of risk, a socially acceptable level of risk, and an economically acceptable level of risk. These are guidelines to quantify risk acceptability. Jonkman et al. (2008) used these 
criteria to analyse how the estimated flood risks (probability of fatalities) in South Holland compare with the acceptable flood risk. Such criteria also allow for the comparison with other societal risks (e.g. chemical and aviation). In the Netherlands, such acceptability criteria are appropriate because a large part of the country is under sea level; therefore, flood risks are highly related to the height of dikes and their standards and resistance. However, in other places, such criteria based on fatalities do not exist with respect to flood risk. For instance, regarding flood early warning systems for rivers in France, thresholds of no, low, medium and high levels of alerts are mainly based on empirical and historical knowledge (for such water levels, a certain damage level occurred in the past), rather than on fatalities or damage probabilities. Thus, one potential utility of the inverse approach would be to be flexible enough to adapt to the various criteria of acceptability that could exist.

Identifying in practice what is acceptable and getting a consensus of stakeholders raises the question of governance, i.e. the coordination of stakeholders, social groups, and institutions to reach a common objective in fragmented and uncertain environments (Bagnasco and Le Galés, 1998). First, it should be noted that flood governance and policy in Europe are changing. The role of the state and individual responsibility for risk management are now key contemporary issues in European flood policy, as highlighted by the 2007/60/EC EU Directive. This policy aims at enhancing the responsibilities of local authorities in flood risk management and reducing the role of national governments, such that local authorities have now to lead partnerships with local stakeholders to ensure effective flood risk management. One of the challenges within the development of a full inverse method is then how to get a consensus between the stakeholders regarding risk acceptability. Some methods have been developed to cope with uncertainty in a complex world (Renn, 2008c) but also to deal with the issue of stakeholders consensus, like the correlation method (Ahmad, 2008), multi-criteria methods like the analytical hierarchy process (Karlsson, 1996), costbenefit methods (Hermann and Daneva, 2008) and group discussion like the TRIAGE method (Gervais and Pepin, 2002).

\section{Conclusions, recommendations, perspective}

The societal significance of a risk and its acceptance not only depends on its physical dimension, but also on its societal perception, which is inherently a context-dependent process and is affected by social, political, cultural and economic factors as recently outlined by the FP7 CapHaz-Net project (Wachinger and Renn, 2010). Thus, in order to ensure an appropriate response for the decision makers, there is a need to develop flexible risk assessment methods regarding the end user needs and triggering their participation.

Knowledge of risk requires estimates of the return period (or exceedance probability) of critical levels of hazard. The proposed methodology intends to achieve the objective of estimating the return period of a given hazard threshold. Assuming that the hazard threshold $\left(R_{\mathrm{C}}\right)$ is known, the two main steps of the methods have been identified: offshore conditions identification (step 1) and assessment of physical return period (or exceedance probability) $T_{\mathrm{R}}$ (step 2). Assuming a critical impact and a plausible level of acceptability, the practicability of steps 1 and 2 is demonstrated using a real case application from southern France.

The inverse method has been proposed as a method that could contribute to raise the risk acceptability question, to provide data for early warning systems, and to trigger stakeholder participation, to improve their awareness and preparedness to potential floods. This article investigated the first development stage of the method. At this stage, several recommendations can be made, based on this preliminary development:

- Provided that a critical asset has been identified (hospital, energy plant, etc.) and that the associated maximum "acceptable" inundation height has been defined, the aforedescribed methodology (step 1 and 2) can be implemented to estimate the return period of exceeding the identified maximum "acceptable" inundation height, for this localised sector. Furthermore, this could be used for localised risk assessment. It can also be used to identify extreme scenarios that were previously thought not possible, like for instance the Xynthia event (Bertin et al., 2012). This type of application falls in the field of stress test design (as it has been developed, for instance, for nuclear plants after the Fukushima earthquake by the West European Nuclear Regulators Association, 2011).

- For early warning systems, the method (step 1) could be used to trigger various levels of alerts. For instance, several critical water levels at the coast can be identified: class 1 (water level reaching the safety minimum altitude of the coast $Z_{\mathrm{c}}$, so that for such $Z_{\mathrm{c}}$, the water level at the coast is just at the limit of flooding), class 2 (water level reaching $1 \mathrm{~m}$ above $Z_{\mathrm{c}}$ ), class 3 (water level $2 \mathrm{~m}$ above $Z_{\mathrm{c}}$ ) and so forth. The inverse method can be used to identify the offshore combinations leading to these classes, such that early warning systems can provide information on water level at the coast, without necessarily running a refined but computationally intensive model every day.

- The final result of the inverse method is the return period of the hazard level judged as the "maximum acceptable" one. The confrontation of this estimate based on pure physical considerations with the one perceived by the population is expected to raise awareness and eventually enhance the preparedness of this society to future events. The proposed inverse method can be viewed as a risk awareness tool allowing the stakeholders to test their territory at risk (Which asset could be flooded? 
What is the return period? Is it different from the one perceived as the "maximum acceptable"? If so, what actions can be undertaken?). Step 1 and 2 of the present method can support these territorial tests.

The proposed inverse method is expected to have strong implications in terms of decision making for coastal risk management. Yet, so that the inverse method fulfils its role in addressing the limitations identified in the introduction (L13 ), a necessary, but challenging next step is to fully address the issue of risk and hazard acceptability. To reach this objective, a possible research line would be vulnerability analysis enabling identification of critical asset(s) and associated critical impact(s) (e.g. asset damage and failure of the asset function), taking into account lifelines (i.e. physical or virtual networks that are vital to health, safety, comfort and economic activity, see, e.g. Platt, 1995) and dependence (i.e. everything an asset depends on, see, e.g. D'Ercole and Metzger, 2009). Such vulnerability analysis, independent of scenario and hazards, could also be useful for multi-risk analysis.

Acknowledgements. The authors thank the ANR VMC 2006 project VULSACO no. ANR-06-VULN-009, the ANR VMC 2007 project MISEEVA no. ANR-07-VULN-007 as well as the BRGMfunded VULNERISK project, for contributions to the financial support of the present work. A. Magnan, M. Poumadère, M. Garcin, C. Oliveros, E. Foerster and A. L. Gautier are acknowledged for fruitful discussions and support. The authors are also grateful to R. Pedreros, V. Turpin and C. Vinchon for their contribution, and to P. Hawkes, resp. Ifremer, for providing the JOIN-SEA, resp. MARS2DH, software. The MISEEVA team working on the public flooding risk representation (specifically C. Meur-Ferec, B. Rulleau, H. Rey-Valette, and their team) is also acknowledged for providing the results of their survey. The authors like also to thank J. Douglas for checking the English. Lastly, J. Beckers, O. Renn and the anonymous reviewer are acknowledged for their constructive comments.

Edited by: O. Katz

Reviewed by: J. Beckers, O. Renn, and one anonymous referee

\section{References}

Ahmad, S.: Negotiation in the Requirements Elicitation and Analysis Process, IEEE, ISBN: 978-0-7695-3100-7, 683-689, 2008.

Ardhuin, F., Bertotti, L., Bidlot, J. R., Cavaleri, L., Filipetto, V., Lefevre, J. M., and Wittmanne, P.: Comparison of wind and wave measurements and models in the Western Mediterranean Sea, Ocean Eng., 34, 526-54, 2007.

Ardhuin, F., Rogers, E., Babanin, A. V., Filipot, J. F., Magne, R., Roland, A., van der Westhuysen, A., Queffeulou, P., Lefevre, J. M., Aouf, L., and Collard, F.: Semi-empirical Dissipation Source Functions for Ocean Waves, Part I: Definition, Calibration, and Validation, J. Phys. Oceanogr., 40, doi:10.1175/2010JPO4324.1, 2010.

Bagnasco, A. and Le Galès, P.: Villes en Europe, Revue française de sociologie, 39-4, 808-810, 1998.
Ballard, G.: Guest editorial: societal risk-progress since Farmer, Reliability Eng. Syst. Safe., 39, 123-127, 1993.

Bertin, X., Bruneau, N., Breilh, J. F., Fortunato, A., and Karpytchev, M.: Importance of wave age and resonance in storm surges : the case of Xynthia, Ocean Modell., 42, 16-30, 2012.

Bonneton, P., Barthelemy, E., Chazel, F., Cienfuegos, R., Lannes, D., Marche, F., and Tissier, M.: Recent advances in Serre-Green Naghdi modelling for wave transformation, breaking and runup processes, Eur. J. Mech. B.-Fluid, 30, 589-597, 2011.

Booij, N., Ris, R. C., and Holthuijsen, L. H.: A third-generation wave model for coastal regions, Part I: Model description and validation, J. Geophys. Res., 104, 7649-7666, 1999.

Bottelberghs, P. H.: Risk analysis and safety policy developments in the Netherlands, J. Hazardous Materials, 71, 59-84, 2000.

Boulahya, F., Dubus, I. G., Dupros, F., and Lombard, P.: Footprint@work, a computing framework for large scale parametric simulations: application to pesticide risk assessment and management, in: Forum EGEE Enabling Grids for E-sciencE, Manchester, UK, 160 pp., 2007.

Cheung, K. F., Phadke, A. C., Wei, Y., Rojas, R., Douyere, Y. J. M., Martino, C. D., Houston, S. H., Liu, P. L. F., Lynett, P. J., Dodd, N., Liao, S., and Nakazaki, E.: Modeling of storm-induced coastal flooding for emergency management, Ocean Eng., 30, 1353-1386, 2003.

Chini, N. and Stansby, P.: Extreme values of coastal wave overtopping accounting for sea level rise and climate change, Coastal Eng., 65, 27-37, doi:10.1016/j.coastaleng.2012.02.009, 2012.

Chini, N., Stansby, P., Rogers, B. D., Vacondio, R., and Mignosa, P.: State-of-the-art coastal inundation models applied to the 2007 Norfolk storm. FLOODRisk conference 2012, in: Comprehensive Flood Risk Management, edited by: Klijn, F. and Schweckendiek, T., Taylor \& Francis Group, London, ISN 978-0-41562144-1, 501-508, 2013.

Ciavola, P., Ferreira, O., Haerens, P., Van Koningsveld, M., and Armaroli, C.: Storm impacts along European coastlines, Part 2: lessons learned from the MICORE project, Environ. Sci. Policy, 14, 924-933, 2011.

Coles, S.: An introduction to Statistical Modelling of Extreme Values, London, Springer Series in Statistics, 2001.

COMRISK: Subproject 1 - Evaluation of policies and strategies for coastal risk management, Directorate-General of Public Works and Water Management - National Institute for Coastal and Marine Management/RIKZ, 2004.

Cunderlik, J. M. and Simonovic, S. P.: Inverse flood risk modelling under changing climatic conditions, Hydrol. Process., 21, 563577, 2007.

Deboudt, P.: Towards coastal risk management in France, Ocean Coast. Manage., 53, 366-378, 2010.

Delta Committee: Working together with Water, Findings of the Deltacommissie, Secretariat Delta committee, the Hague, the Netherlands, available at: http://www.deltacommissie.com/doc/ deltareport_full.pdf (last access: 1 March 2012), 2008.

DELTARES: Flood Risk Management, available at: http://www. deltares.nl/xmlpages/TXP/files?p_file_id=14056 (last access: 3 April 2013), 2010.

D'Ercole, R. and Metzger, P.: La vulnérabilité territoriale: une nouvelle approche des risques en milieu urbain, Cybergeo: European Journal of Geography, Dossiers, Vulnérabilités urbaines au sud, article 447, mis en ligne le 31 mars 2009, available at: http:// 
cybergeo.revues.org/22022; doi:10.4000/cybergeo.22022, 2009.

Divoky, D. and McDougal, W. G.: Response-based coastal flood analysis, Proc. 30th ICCE, ASCE, 5291-5301, 2006.

Douglas, J., Ulrich, T., and Negulescu, N.: Risk-targeted seismic design maps for mainland France, Nat. Hazards, 65, 1999-2013, doi:10.1007/s11069-012-0460-6, 2013.

EU: Directive 2007/60/EC of the European parliament and of the council of 23 October 2007 on the assessment and management of flood risks, 2007.

Farmer, F. R.: Siting criteria - a new approach, Atom, 128, 152179, 1967.

FEMA: Wave runup and overtopping, FEMA Coastal Flood Hazard Analysis and Mapping Guidelines Focused Study Report, 51 pp., 2005.

FEMA: Guidelines and specifications for Flood Hazard Mapping Partners, 2011.

Freeman, E.: The Stakeholder Approach Revisited, Z. Wirtschafts Unternehmensethik, 5, 220-241, 2004.

Gamper, C. D. and Turcanu, C.: Can public participation help managing risks from natural hazards?, Safety Sci., 47, 522-528, doi:10.1016/j.ssci.2008.07.005, 2009.

Garrity, N. J., Battalio, R., Hawkes, P. J., and Roupe, D.: Evaluation of the event and response approaches to estimate the 100-year coastal flood for Pacific coast sheltered waters, Proc. 30th ICCE, ASCE, 1651-1663, 2006.

Gerritsen, H.: What happened in 1953? The Big Flood in the Netherlands in retrospect, Phil. Trans. R. Soc. A, 363, 12711291, doi:10.1098/rsta.2005.1568, 2005.

Gervais, M. and Pépin, G.: TRIAGE: a new group technique gaining recognition in evaluation, Evaluation J. Australasia, 2, 45-9, 2002.

Haimes, Y. Y.: Risk of Extreme Events and the Fallacy of the Expected Value, in: Risk Modeling, Assessment and Management, edited by: Sage, A. P., John Wiley \& Sons, Hoboken, 299-321, 2004.

Haldar, A. and Mahadevan, S.: Probability, reliability, and statistical methods in engineering design, Wiley, New York, 2000.

Harley, M., Valentini, A., Armaroli, C., Ciavola, P., Perini, L., Calabrese, L., and Marucci, F.: An early warning system for the on-line prediction of coastal storm risk on the Italian coastline, Coast. Eng. Proceed., 1, doi:10.9753/icce.v33.management.77, online first, 2012.

Hawkes, P. J., Gouldby, B. P., Tawn, J. A., and Owen, M. W.: The joint probability of waves and water levels in coastal engineering design, J. Hydraul. Res., 40, 241-251, doi:10.1080/00221680209499940, 2002.

Herrmann, A. and Daneva, M.: Requirements Prioritization Based on Benefit and Cost Prediction, 16th IEEE International Requirements Engineering Conference, doi:10.1109/RE.2008.48, 2008.

Hervouet, J.-M. and Van Haren, L.: Recent advances in numerical methods for fluid flows, in: Floodplain Processes, edited by: Anderson, M. G., Walling, D. E., Bates, P. D., Wiley, Chichester, 183-214, 1996.

HR Wallingford with Lancaster University: The joint probability of waves and water levels: JOIN-SEA: A rigorous but practical new approach, HR Report SR 537, 2000a.

HR Wallingford: The Joint Probability of Waves and Water Levels: JOIN-SEA - Version 1.0, User Manual, Report TR71, $2000 \mathrm{~b}$.
Jonkman, S. N., Kok, M., and Vrijlin, J. K.: Flood Risk Assessment in the Netherlands: A Case Study for Dike Ring South Holland, Risk Anal., 28, 1357-1373, doi:10.1111/j.15396924.2008.01103.x, 2008.

Karlsson, J.: Software Requirements Prioritizing, ISBN: 0-81867252-8, IEEE, 110-116, 1996.

Kasperson, R. E.: Six Propositions on Public Participation and Their Relevance for Risk Communication, Risk Anal., 6, 275-281, doi:10.1111/j.1539-6924.1986.tb00219.x, 1986.

Kennedy, M. C. and O'Hagan, A.: Bayesian Calibration of Computer Models, J. Roy. Stat. Soc., 63, 425-464, 2001.

Kievik, M. and Gutteling, J. M.: Yes, we can: motivate Dutch citizens to engage in self-protective behavior with regard to flood risks, Nat. Hazards, 59, 1475-1490, doi:10.1007/s11069-0119845-1, 2011.

Kirwan, B., Hall, A., and Hopkins A.: Changing regulation - Controlling risk in society, Oxford, Pergamon, 2002.

Kwadijk, J. C. J., Haasnoot, M., Mulder, J. P. M., Hoogvliet, M. M. C., Jeuken, A. B. M., van der Krogt, R. A. A., van Oostrom, N. G. C., Schelfhout, H. A., van Velzen, E. H., van Waveren, H., and de Wit, M. J. M.: Using adaptation tipping points to prepare for climate change and sea level rise: a case study in the Netherlands, WIREs Clim Change, 1, 729-740, doi:10.1002/wcc.64, 2010.

Lazure, P. and Dumas, F.: An external-internal mode coupling for a 3D hydrodynamical model for applications at regional scale (MARS), Adv. Water Res., 31, 233-250, 2008.

Lyard, F., Lefevre, F., Letellier, T., and Francis, O.: Modelling the global ocean tides: modern insights from FES2004, Ocean Dynam., 56, 394-415, doi:10.1007/s10236-006-0086-x, 2006.

Meyer, V., Kuhlicke, C., Luther, J., Fuchs, S., Priest, S., Dorner, W., Serrhini, K., Pardoe, J., McCarthy, S., Seidel, J., Palka, G., Unnerstall, H., Viavattene, C., and Scheuer, S.: Recommendations for the user-specific enhancement of flood maps, Nat. Hazards Earth Syst. Sci., 12, 1701-1716, doi:10.5194/nhess-121701-2012, 2012.

Nicholls, R. J., Hanson, S. E., Lowe, J. A., Vaughan, D. A., Lenton, T., Ganopolski, A., Tol, R. S. J., and Vafeidis, A. T.: Improving methodologies to assess the benefits of policies to address sealevel rise, Report to OECD, Paris, 135 pp., 2006.

Norbiato, D., Borga, M., Esposti, S. D., Gaume, E., and Anquetin, S.: Flash flood warning based on rainfall thresholds and soil moisture conditions: An assessment for gauged and ungauged basins, J. Hydrol., 362, 274-290, 2008.

O’Sullivan, J. J., Bradford, R. A., Bonaiuto, M., De Dominicis, S., Rotko, P., Aaltonen, J., Waylen, K., and Langan, S. J.: Enhancing flood resilience through improved risk communications, Nat. Hazards Earth Syst. Sci., 12, 2271-2282, doi:10.5194/nhess-122271-2012, 2012.

Pedreros, R., Vinchon, C., Delvallée, E., Lecacheux, S., Balouin, Y., Garcin, M., Krien, Y., Le Cozannet, G., Poisson, B., Thiebot, J., Marche, F., and Bonneton, P.: Using a multi models approach to assess coastal exposure to marine inundation within a global change context, Geophys. Res. Abstr., Vol. 13, EGU2011-13679, EGU General Assembly 2011, Vienna, Austria, 2011.

Picheny, V., Ginsbourger, D., Richet, Y., and Caplin, G.: Quantile-Based Optimization of Noisy Computer Experiments with Tunable Precision, Technometrics, 55, 2-13, doi:10.1080/00401706.2012.707580, 2013. 
Platt, R. H.: Lifelines : an emergency management priority for the United States in the 1990s, Disasters, 15, 172-176, 1995.

Renn, O.: Concepts of Risk: An Interdisciplinary Review - Part 1: Disciplinary Risk Concepts GAIA 17/1(2008), 50-66, 2008a.

Renn, O.: Concepts of Risk: An Interdisciplinary Review - Part 2: Integrative Approaches GAIA 17/2(2008), 196-204, 2008b.

Renn O.: Risk Governance: Coping with uncertainty in a complex world, London, Eathscan, 455 pp., 2008c.

Rohmer, J. and Idier, D.: A meta-modelling strategy to identify the critical offshore conditions for coastal flooding, Nat. Hazards Earth Syst. Sci., 12, 2943-2955, doi:10.5194/nhess-12-29432012, 2012.

Safecoast: Coastal flood risk and trends for the future in the North Sea region, synthesis report, Safecoast project team, The Hague, 136 pp., 2008.

Saha, S., Moorthi, S., Pan, H.-L., Wu, X., Wang, J., Nadiga, S., Tripp, P., Kistler, R., Woollen, J., Behringer, D., Liu, H., Stokes, D., Grumbine, R., Gayno, G., Wang, J., Hou, Y.-T., Chuang, H., Juang, H.-M. H., Sela, J., Iredell, M., Treadon, R., Kleist, D., Van Delst, P., Keyser, D., Derber, J., Ek, M., Meng, J., Wei, H., Yang, R., Lord, S., van den Dool, H., Kumar, A., Wang, W., Long, C., Chelliah, M., Xue, Y., Huang, B., Schemm, J.-K., Ebisuzaki, W., Lin, R., Xie, P., Chen, M., Zhou, S., Higgins, W., Zou, C.-Z., Liu, Q., Chen, Y., Han, Y., Cucurull, L., Reynolds, R. W., Rutledge, G., and Goldberg, M.: The NCEP Climate Forecast System Reanalysis, B. Am. Meteorol. Soc., 91, 1015-1057, doi:10.1175/2010BAMS3001.1, 2010.

Stockdon, H. F., Holman, R. A., Howd, P. A., and Sallenger, A. H.: Empirical parameterization of setup, swash, and runup, Coast. Eng., 53, 573-588, 2006.

UNISDR: UNISDR Terminology on Disaster Risk Reduction, 2009.

Van der Most, H. and Wehrung, M.: Dealing with Uncertainty in Flood Risk Assessment of Dike Rings in the Netherlands, Nat. Hazards, 36, 191-206, 2005.
Vinchon, C., Aubie, S., Balouin, Y., Closset, L., Garcin, M., Idier, D., and Mallet, C.: Anticipate response of climate change on coastal risks at regional scale in Aquitaine and Languedoc-Roussillon (France), Ocean Coast. Manage., 52, 4756, doi:10.1016/j.ocecoaman.2008.09.011, 2008.

Vinchon, C., Baron-Yelles, N., Berthelier, E., Hérivaux, C., Lecacheux, S., Meur-Ferec, C., Pedreros, R., Rey-Valette, H., and Rulleau, B.: MISEEVA: Set up of a transdisciplinary approach to assess vulnerability of the coastal zone to marine inundation at regional and local scale, within a global change context, Littoral2010, London, 2010.

Vrijling, J. K., van Hengel, W., and Houben, R. J.: A framework for risk evaluation, J. Hazardous Materials, 43, 245-261, 1995.

von Storch, H., Gönnert, G., Meine, M., and Woth, K.: Storm surges - an option for Hamburg, Germany, to mitigate expected future aggravation of risk, Environ. Sci. Policy., 11, 735-742, doi:10.1016/j.envsci.2008.08.003, 2008.

Wachinger, G. and Renn, O.: Risk Perception and Natural Hazards, CapHaz-Net WP3 Report, DIALOGIK NonProfit Institute for Communication and Cooperative Research, Stuttgart, available at: http://caphaz-net.org/outcomes-results/ CapHaz-Net_WP3_Risk-Perception2.pdf (last access: 3 April 2013), 2010.

Wadey, M. P., Nicholls, R. J., and Hutton, C.: Coastal Flooding in the Solent: An Integrated Analysis of Defences and Inundation, Water, 4, 430-459, 2012.

WENRA: The proposal by the WENRA Task Force about "Stress tests" specifications, available at: http://www.wenra.org/dynamaster/file_archive/ 110421/0ea2c97b35d658d73d1013f765e0c87d/

StressTestsSpecifications2011-04-21.pdf (last access: 3 April 2013), 2011. 